\title{
Evolución del delta del río Paraná y su posible vinculación con el calentamiento global
}

\author{
Rubén Alberto MEDINA ${ }^{1,2}$ \& Jorge Osvaldo CODIGNOTTO ${ }^{3,4}$
}

\begin{abstract}
${ }^{1}$ Departamento de Ciencias Geológicas, Facultad de Ciencias Exactas y Naturales, UBA, Ciudad Universitaria, Pabellón II, 1ํ Piso, (C1428EGA) CABA, Argentina. e-mail: medinaruben01@yahoo.com.ar. ${ }^{2}$ Departamento de Agrimensura, Facultad de Ingeniería, UBA, Av. Las Heras 2214, $3^{\circ}$ Piso, (C1127AAR) CABA, Argentina. ${ }^{3}$ Servicio Geológico Minero Argentino (SEGEMAR), Parque Tecnológico Miguelete, Edificio 25, Av. General Paz 5445, (1650) San Martín, Buenos Aires, Argentina. ${ }^{4}$ CONICET, Consejo Nacional de Investigaciones Científicas y Técnicas, Av. Rivadavia 1917, (C1033AAJ) CABA, Argentina
\end{abstract}

\begin{abstract}
Evolution of the Paraná River Delta and its possible relationship to Global warming. This paper discusses the recent geomorphological evolution of the Paraná River Delta on the basis of cadastral information, old topographic and nautical charts and satellite images. This evolution is linked to the consequences of global warming in the region of the Río de la Plata, particularly to the erosive processes. These processes are very active in areas close to the delta, especially in the Samborombón Bay. However, in the Paraná Delta not there was a decrease in their rhythm of progradation, on the contrary, it has remained constant or even has quickened. This is probably due to increased sedimentary load by the Paraná River in response to the increase of precipitation recorded since the 1970s in the region center and north of Argentina. As this is a direct consequence of global warming, or local climate variability, it may be said that the climate factor is also responsible for the aforementioned progradational dynamics.
\end{abstract}

Key words: Paraná Delta, evolution, Global warming, Río de la Plata, Samborombón Bay

Resumen: Se analiza la reciente evolución geomorfológica del delta del río Paraná en base a información catastral, antiguas cartas topográficas y náuticas e imágenes satelitales. Esta evolución es vinculada a las consecuencias del calentamiento global en la región del Río de la Plata, particularmente a los procesos erosivos. Estos procesos son muy activos en sectores próximos al delta, especialmente en la bahía Samborombón. Sin embargo, en el delta del Paraná no se ha registrado una disminución en su ritmo de avance, por el contrario, éste se ha mantenido constante o incluso se ha acelerado. Esto se debe seguramente a una mayor carga sedimentaria por parte del río Paraná en respuesta al incremento de las precipitaciones registradas desde la década del 70 en la región centro y norte de Argentina. Al ser esto una consecuencia directa del calentamiento global, o en su defecto, de la variabilidad climática local, se puede afirmar que el factor climático es también responsable de la dinámica progradacional anteriormente citada.

Palabras clave: delta del Paraná, evolución, calentamiento global, Río de la Plata, bahía Samborombón

\section{INTRODUCCIÓN}

El calentamiento global forma parte de una realidad que se impone a la sociedad por su indiscutible trascendencia. Los sucesivos informes desde 1990 en adelante del Panel Intergubernamental para el Cambio Climático, han proporcionado suficiente información que confirma lo anteriormente expuesto (IPCC, 1990, 1995, 2001, 2007).

En el Río de la Plata este proceso se ha puesto de manifiesto de múltiples y diversas formas. En el sector costero, Codignotto y Ercolano (2006) y
Codignotto (2009) notaron que durante la década del '90 aumentó la erosión en Punta Piedras y Punta Rasa (Fig. 1). En bahía Samborombón, Codignotto et al. (2011a) y Codignotto et al. (2012) estimaron para el período 1961-2009 un retroceso medio del microacantilado de $1 \mathrm{~m} / \mathrm{año}$, siendo este valor quizás no representativo de la actual situación pues las mediciones de campo llevadas a cabo durante el año 2010 señalaron valores de retroceso significativamente mayores, superando incluso los 2,5 m/año. Por su parte, Kokot (1999) reportó un incremento en los procesos erosivos a lo largo de la costa de la provincia de Buenos 


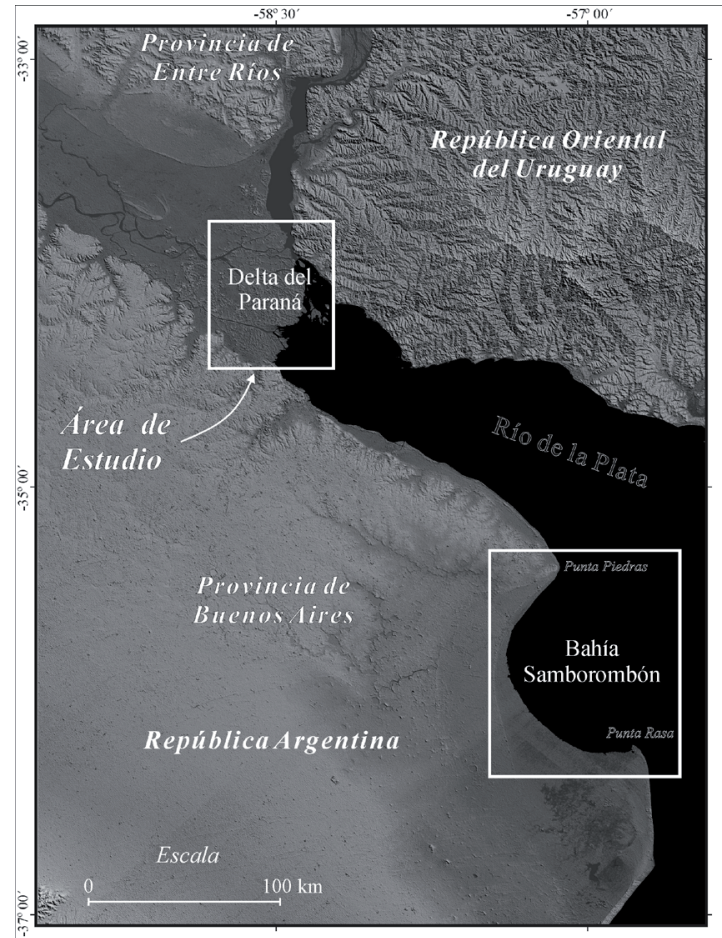

Fig. 1. Localización del área de estudio. La imagen presenta exageración vertical con el fin de mejorar la visualización de las bajas áreas costeras (en gris oscuro). Se señala también la bahía Samborombón, área cercana geográficamente al delta del río Paraná, que probablemente ha sufrido el incremento en el retroceso de su costa a causa del actual calentamiento global. Fuente: International Centre for Tropical Agriculture (CIAT) disponible en http://srtm.csi.cgiar.org

Aires durante las últimas tres décadas del siglo pasado, vinculando dicho aumento con cambios en los procesos oceánicos y atmosféricos. En otro aspecto, Gibson (1992) mostró que la posición media zonal de la corriente en chorro subtropical del Hemisferio Sur ha sufrido un desplazamiento de aproximadamente $3^{\mathrm{o}}$ de latitud hacia el sur durante el período 1976-1991. Escobar et al. (2003) encontraron que el borde occidental del anticiclón semipermanente del Atlántico Sur se ha desplazado lentamente hacia el sur durante las últimas décadas, provocando en la región del Río de la Plata un incremento en la frecuencia de los vientos provenientes del sector este, entre otras cosas. Este mismo desplazamiento fue reportado por Camilloni $(1999,2005)$ y Camilloni et al. (2005), en tanto que un incremento en la frecuencia de los vientos del este fue señalado por Simionato et al. (2005) para los meses de verano e invierno tanto en el estuario del Río de la Plata como en la plataforma adyacente. Asimismo, las estadísticas de vientos de superficie observadas en el aeropuerto Jorge Newbery de la ciudad de Buenos Aires para los períodos 1981-1990 y 1991-2000, mostraron también un aumento en la frecuencia y velocidad de los vientos del este. Comparando ambas décadas se detectó un leve incremento en las frecuencias de los vientos del este y noreste pasando, respectivamente, de $18,4 \%$ al $22,0 \%$ y de $11,5 \%$ al $13,5 \%$, en tanto que la velocidad promedio de los primeros pasó de 4,4 $\mathrm{m} / \mathrm{s}$ a $5,3 \mathrm{~m} / \mathrm{s}$ (SMN, 1992, 2009).

Los cambios registrados en los vientos tienen un efecto directo sobre el oleaje. Este tema fue tratado por Kokot $(1997,2010)$ al estudiar la relación existente entre la configuración del contorno costero y la dinámica litoral imperante en diversos sectores de la costa argentina. Por su parte, Codignotto et al. (2011b), Codignotto et $a l$. (2012) y Dragani et al. (2012) detectaron, mediante el empleo de simulaciones numéricas, un leve incremento en las alturas de olas desde 1970 al presente en el Río de la Plata y océano adyacente. A su vez, los cambios en las frecuencias y alturas de olas debido a las tormentas en el Río de la Plata, localmente denominadas sudestadas, fueron reportados por Escobar et al. (2004). Estos últimos autores analizaron la frecuencia anual de las sudestadas durante las últimas cinco décadas del siglo pasado, observando un incremento en el total de eventos, al pasar de 44 casos en la década del '60 a 79 registros en los ' 90.

Por último, Lanfredi et al. (1998) estimaron que el nivel medio del mar en la costa de la ciudad de Buenos Aires ascendió a razón de $+1,6 \pm 0,1$ $\mathrm{mm} / \mathrm{año}$, al menos durante el período por ellos analizado (1905-1992). En tanto el nivel del mar mundial, según los datos proporcionados por el NOAA (Laboratory for satellite Altimetry Global $\mathrm{S} 60^{\circ}-\mathrm{N} 60^{\circ}$ ) registró un ascenso de $2,7 \mathrm{~mm} /$ año entre los años 1993 y 2012 (O’ Day, 2012).

En síntesis, los cambios observados tales como el aumento del nivel medio del mar, el incremento en la frecuencia de eventos de tormentas marítimas (sudestadas) y el cambio en la dirección, frecuencia y velocidad de los vientos con su correlato en la frecuencia, altura y dirección de olas, produjeron necesariamente una redistribución, e incluso un incremento del flujo de energía puesto en juego en esta región. La intensificación de los procesos erosivos y los cambios morfodinámicos percibidos desde hace algunos años en el área de la bahía Samborombón, constituyen probablemente un claro ejemplo del ajuste de ese sector a las nuevas magnitudes de las variables intervinientes en el modelado costero. 
En este trabajo se discuten las posibles implicancias del calentamiento global en el área del delta del río Paraná, sector próximo a la bahía Samborombón, con la que comparte además de su proximidad geográfica, su escasa cota respecto del nivel medio del mar y su mínima alteración antrópica del paisaje, siendo estas condiciones necesarias para una exacta evaluación de la relevancia de los forzantes climáticos en la evolución geomorfológica del sector analizado (Fig. 1).

\section{Área de estudio}

La desembocadura del río Paraná en el Río de la Plata da origen a un típico delta de cabecera de estuario, parcialmente lobado, con su parte convexa en dirección al cuerpo de agua receptor. El delta es una típica forma de agradación progradante que se caracteriza por presentar amplios canales con albardones bien desarrollados constituidos por sedimentos limo-arenosos a arenosos finos, que encierran depresiones centrales ocupadas por lagunas permanentes o semipermanentes. Según Malvárez (1997), las periódicas inundaciones de estos sectores le confieren a esta región las características propias de un humedal fluvio-costero.

El delta del Paraná nace precisamente en la bifurcación del río homónimo en sus dos grandes brazos, el Paraná Guazú al norte y el Paraná de las Palmas al sur. El primero presenta sucesivas divisiones hasta desembocar en el tramo final del río Uruguay. El segundo discurre prácticamente en forma paralela a la paleocosta noreste bonaerense. Esta unidad, con forma groseramente triangular, tiene una longitud de 80 a $90 \mathrm{~km}$ en dirección ONO, una superficie de $3830 \mathrm{~km}^{2}$, un frente costero entre las desembocaduras de los ríos Luján y Gutiérrez de 120 km (y de más de $225 \mathrm{~km}$ contabilizando las islas), y una cota promedio de $2 \mathrm{~m}$, reduciéndose a menos de $1 \mathrm{~m}$ sobre el nivel medio del mar en la franja costera propiamente dicha.

Los sedimentos que conforman el delta son aportados principalmente por el río Paraná. Según Soldano (1947), el caudal medio de este río a la altura de la ciudad de Rosario es de 16120 $\mathrm{m}^{3} / \mathrm{s}$ con caudales máximos de hasta $65000 \mathrm{~m}^{3} / \mathrm{s}$, al menos en la primera mitad del siglo XX. La carga sedimentaria alcanza los 160 millones $\mathrm{tn} /$ año, distribuida granulométricamente en un $28 \%$ de arcillas, un 56\% de limos y un 16\% de arenas (Sarubbi, 2007). De este total, al menos $100 \mathrm{mi}-$ llones tn/año son aportados por el río Bermejo, uno de los principales afluentes del río Paraguay, siendo éste el principal tributario del Paraná.
Por su parte, el río Uruguay no realiza aportes sedimentarios significativos para el avance del delta, pero sí actúa como modelador de su frente costero al redistribuir los sedimentos acarreados por el Paraná, en particular los provenientes del Paraná Guazú y sus distributarios. Otros factores que intervienen activamente en el modelado de este frente son las mareas de rango micromareal, es decir menores a dos metros, y especialmente las tormentas atlánticas (sudestadas) con las olas y corrientes litorales asociadas.

Jurisdiccionalmente el delta está repartido entre las provincias de Buenos Aires $(70,27 \%)$ y Entre Ríos (29,39\%). No obstante, el constante aporte sedimentario y avance del frente costero ha posibilitado el continuo crecimiento de las islas Juncal (Uru) y Juncalito (Uru), el adosamiento de la isla Timoteo Domínguez (Uru) a Martín García (Arg) y la aparición del islote El Matón (Uru). En total, la superficie acrecionada por la República Oriental del Uruguay ha sido de 13,16 $\mathrm{km}^{2}$, representando aproximadamente el 0,34\% de la superficie total del delta del río Paraná.

Debido a la importancia de los humedales a nivel mundial, cabe remarcar que en el año 2000 se incorporaron aproximadamente unas 90000 ha del partido de San Fernando, provincia de Bs As (secciones $2^{\circ}$ y $3^{\circ}$ del Delta del Paraná), a la Red Mundial de Reservas de Biosfera del Programa "El Hombre y la Biosfera (MAB) de UNESCO", con el fin de conservar y promover el desarrollo ecológicamente sustentable de esta región.

\section{Antecedentes}

El primer estudio científico del área del delta del río Paraná se remonta al informe efectuado por el Dr. Francisco Muñiz, presumiblemente en el año 1818 (Muñiz, 1925), quien, según Vignati (1925), fue autor también de un preciso mapa del área comprendida al sur del río Paraná Miní. De dicha representación cartográfica se basó el Ing. Soldano para establecer una progradación de 70 $\mathrm{m} / \mathrm{año}$ en el sector próximo a la margen izquierda del río Paraná de las Palmas, señalando que dicho crecimiento no es uniforme a lo largo de toda la costa, siendo aproximadamente de $90 \mathrm{~m} / \mathrm{año}$ en el sector comprendido entre los ríos Paraná de las Palmas y Luján, y de 55 m/año en el sector ubicado entre el Paraná de las Palmas y el Guazú, al menos durante el período 1912-1943 (Soldano, 1947). Por su parte, el Dr. Pablo Groeber realizó uno de los primeros relevamientos geológicos del área a comienzos de la década del 60 (Groeber, 1961). Más tarde, Iriondo y Scotta (1979), Iriondo $(1980,2004)$ y Cavallotto et al. (2005) 


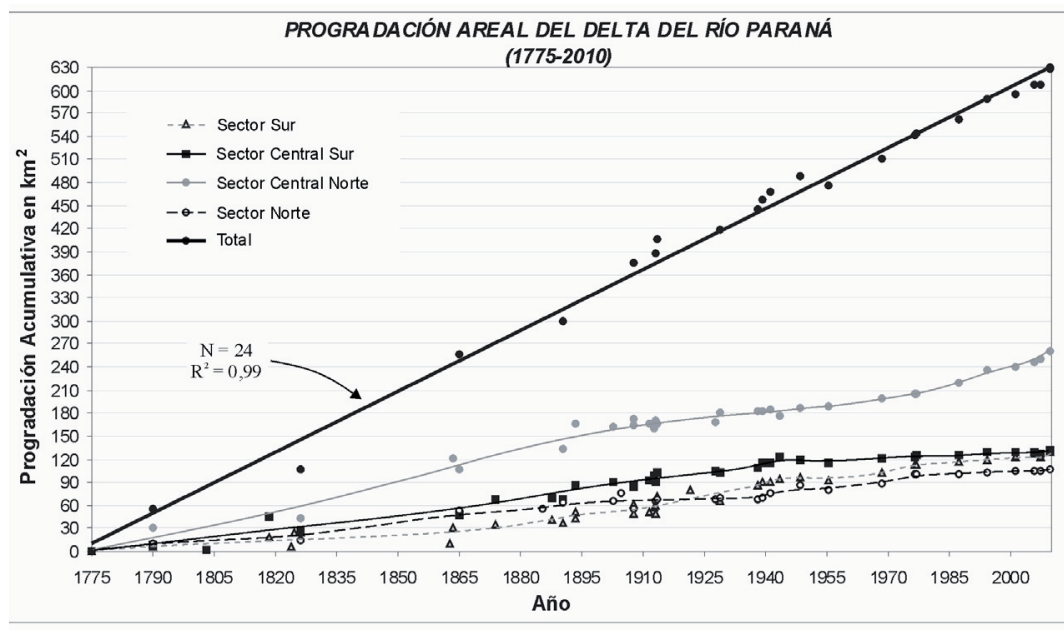

Fig. 2. Crecimiento areal del delta del río Paraná correspondiente al período 1775-2010. Se aprecia la clara tendencia acrecional lineal del conjunto, a diferencia de las tendencias variables y disímiles de sus partes constituyentes. realizaron un exhaustivo análisis de la evolución Holocena del complejo litoral ubicado en la desembocadura del río Paraná. Trabajos posteriores se abocaron al estudio en detalle de la evolución del sector distal del mencionado complejo, denominado Delta Inferior o simplemente Delta del Paraná (Codignotto, 1990, 1996; Codignotto et al., 1996; Medina, 2004; Codignotto \& Medina, 2005, 2011; Sarubbi et al., 2006; Sarubbi, 2007; Medina \& Codignotto, 2011; entre otros). Por último, Codignotto y Medina (2005), Medina et al. (2011), y Medina y Codignotto (2012) señalaron la estrecha relación existente entre la más reciente evolución geomorfológica del área en cuestión y el actual calentamiento global.

\section{MATERIALES Y MÉTODOS}

Con el fin de evaluar la evolución geomorfológica reciente se recurrió al análisis multitemporal empleando para ello información catastral, antiguas cartas topográficas y náuticas e imágenes satelitales. Debido a la precisión y exactitud requerida, en todos los casos fue necesario la georreferenciación del material empleado y la utilización de programas informáticos. Este tipo de estudio es característico en el análisis de los deltas del mundo, siendo los casos de los deltas del Danubio, en Rumania (Bird, 2008), del Padang, en Indonesia (Nossin, 1965), del GangesBrahmaputra, en India y Bangladesh (Allison, 1998) y del Po, en Italia (Berghaus, citado en De Lapparent, 1906) típicos ejemplos del empleo de esta metodología.

En este trabajo el lapso temporal analizado abarcó un total de 235 años (período 1775-2010), utilizándose un total de nueve imágenes sateli- tales (Landsat y Spot) y treinta y cinco imágenes en papel. El método consistió en comparar la cartografía más antigua con el material más reciente, cuantificando tanto el crecimiento areal como el avance lineal en diferentes sectores del área estudiada.

Debido a que el material cartográfico es escaso y que no siempre contempla la totalidad del sector bajo análisis, se recurrió para su mejor aprovechamiento a la subdivisión del área en cuatro sectores. El sector norte quedó comprendido entre los ríos Paraná Bravo y Gutiérrez y el Paraná Guazú, el sector central norte entre el Paraná Guazú y el Paraná Miní, el sector central sur entre el Paraná Miní y el Paraná de las Palmas, y el sector sur entre este último río y el Luján. Por otra parte, esta subdivisión permitió una más adecuada representación cartográfica de los sucesivos límites de los diferentes frentes costeros del delta del río Paraná durante el período analizado.

\section{RESULTADOS}

Del detallado análisis del material cartográfico se desprende que en el período 1775-2010 el delta del Paraná creció aproximadamente 630 $\mathrm{km}^{2}$ a razón de 264 ha/año. Este avance presenta una clara tendencia lineal $\left(\mathrm{R}^{2}=0,99\right)$ que no se refleja en ninguno de los sectores en los que se ha subdividido el área para su estudio, presentando éstos tendencias acrecionales relativamente variables y disímiles entre sí (Fig. 2).

Con estos datos y con el apoyo de la cartografía correspondiente, se elaboró un mapa en el cual quedaron reflejados sucesivos frentes costeros del delta del Paraná para los últimos 260 


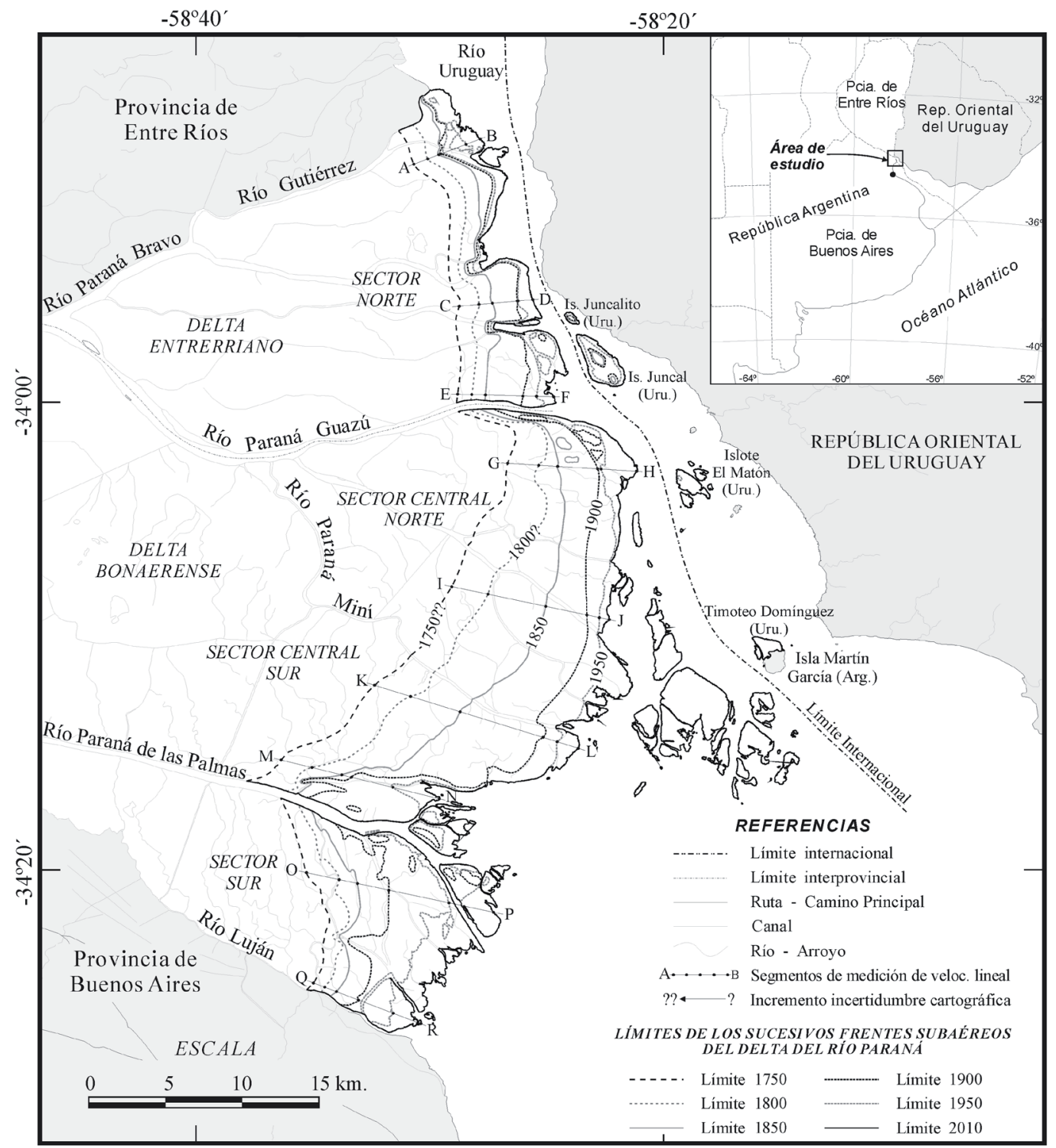

Fig. 3. Progradación del delta del río Paraná para los últimos 260 años (período 1750-2010). Al no contar con cartografía confiable, para la confección del límite del año 1750 se asumió una evolución similar al período con datos fiables más próximo (1775-1780).

años (Fig. 3). Cabe destacar que la incertidumbre en el establecimiento de los diferentes límites se acrecienta con la antigüedad de éstos, ya que en cartografía tanto la exactitud como la precisión espacial y temporal decrecen sensiblemente con la edad del material empleado.

La elaboración de este mapa permitió efectuar mediciones de velocidades promedio de progradación lineal para diferentes períodos de tiempo a lo largo de nueve ejes distribuidos a lo ancho del sector analizado (Fig. 4).
Del análisis de velocidades se desprende que para el período 1750-2010 el sector norte presenta las menores velocidades promedio de crecimiento lineal (segmentos A-B, C-D y E-F) al progradar unos 20 m/año (Fig. 4D). En cambio, las mayores velocidades se presentan en la franja ubicada entre la parte media del sector central norte y la parte superior del sector sur (segmentos I-J, $\mathrm{K}-\mathrm{L}, \mathrm{M}-\mathrm{N}$ y O-P), con un avance promedio anual de 46 metros. La parte meridional del sector sur avanza a una velocidad intermedia entre las dos 


\begin{tabular}{|c|c|c|c|c|c|c|c|c|}
\hline \multicolumn{9}{|c|}{ VELOCIDADES PROMEDIO DE CRECIMIENTO LINEAL } \\
\hline \multicolumn{3}{|c|}{ Período $\longrightarrow$} & $1750-1800$ & $1800-1850$ & $1850-1900$ & $1900-1950$ & $1950-2010$ & $1750-2010$ \\
\hline \multirow{9}{*}{ 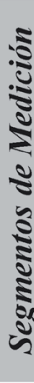 } & \multirow{3}{*}{$\begin{array}{l}\dot{\bar{\nu}} \\
\dot{z} \\
\dot{\omega}\end{array}$} & $A-B$ & $19,77 \mathrm{~m} / \mathrm{a}$ & $16,04 \mathrm{~m} / \mathrm{a}$ & $3,17 \mathrm{~m} / \mathrm{a}$ & $32,73 \mathrm{~m} / \mathrm{a}$ & $20,30 \mathrm{~m} / \mathrm{a}$ & $18,47 \mathrm{~m} / \mathrm{a}$ \\
\hline & & $C-D$ & $26,16 \mathrm{~m} / \mathrm{a}$ & $17,63 \mathrm{~m} / \mathrm{a}$ & $33,36 \mathrm{~m} / \mathrm{a}$ & $0,76 \mathrm{~m} / \mathrm{a}$ & $16,29 \mathrm{~m} / \mathrm{a}$ & $18,74 \mathrm{~m} / a$ \\
\hline & & $E-F$ & $18,56 \mathrm{~m} / \mathrm{a}$ & $17,95 \mathrm{~m} / \mathrm{a}$ & $49,36 \mathrm{~m} / \mathrm{a}$ & $17,95 \mathrm{~m} / \mathrm{a}$ & $18,82 \mathrm{~m} / \mathrm{a}$ & $24,31 \mathrm{~m} / \mathrm{a}$ \\
\hline & \multirow{4}{*}{ 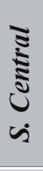 } & $G-H$ & $41,06 \mathrm{~m} / \mathrm{a}$ & $24,90 \mathrm{~m} / \mathrm{a}$ & $52,70 \mathrm{~m} / \mathrm{a}$ & $4,61 \mathrm{~m} / \mathrm{a}$ & $39,03 \mathrm{~m} / \mathrm{a}$ & $32,71 \mathrm{~m} / \mathrm{a}$ \\
\hline & & $I-J$ & $48,98 \mathrm{~m} / \mathrm{a}$ & $78,18 \mathrm{~m} / \mathrm{a}$ & $55,76 \mathrm{~m} / \mathrm{a}$ & $16,94 \mathrm{~m} / \mathrm{a}$ & $11,21 \mathrm{~m} / \mathrm{a}$ & $41,02 \mathrm{~m} / a$ \\
\hline & & $K-L$ & $50,30 \mathrm{~m} / \mathrm{a}$ & $69,30 \mathrm{~m} / \mathrm{a}$ & $115,98 \mathrm{~m} / \mathrm{a}$ & $20,20 \mathrm{~m} / \mathrm{a}$ & $24,55 \mathrm{~m} / \mathrm{a}$ & $54,85 \mathrm{~m} / \mathrm{a}$ \\
\hline & & $M-N$ & $41,98 \mathrm{~m} / \mathrm{a}$ & $40,32 \mathrm{~m} / \mathrm{a}$ & $13,70 \mathrm{~m} / \mathrm{a}$ & $55,58 \mathrm{~m} / \mathrm{a}$ & $54,20 \mathrm{~m} / \mathrm{a}$ & $41,66 \mathrm{~m} / \mathrm{a}$ \\
\hline & 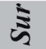 & $O-P$ & $44,02 \mathrm{~m} / \mathrm{a}$ & $24,72 \mathrm{~m} / \mathrm{a}$ & $42,64 \mathrm{~m} / \mathrm{a}$ & $81,54 \mathrm{~m} / \mathrm{a}$ & $49,87 \mathrm{~m} / \mathrm{a}$ & $48,61 \mathrm{~m} / \mathrm{a}$ \\
\hline & $\dot{\varphi}$ & $Q-R$ & $16,23 \mathrm{~m} / \mathrm{a}$ & $16,83 \mathrm{~m} / \mathrm{a}$ & $31,74 \mathrm{~m} / \mathrm{a}$ & $49,90 \mathrm{~m} / \mathrm{a}$ & $32,88 \mathrm{~m} / \mathrm{a}$ & $29,65 \mathrm{~m} / \mathrm{a}$ \\
\hline
\end{tabular}
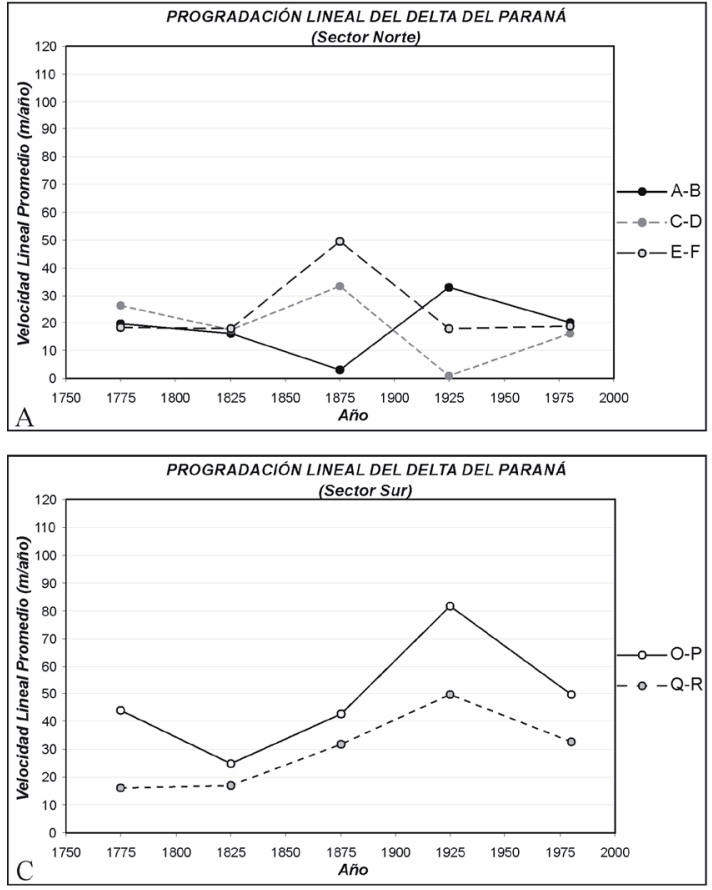

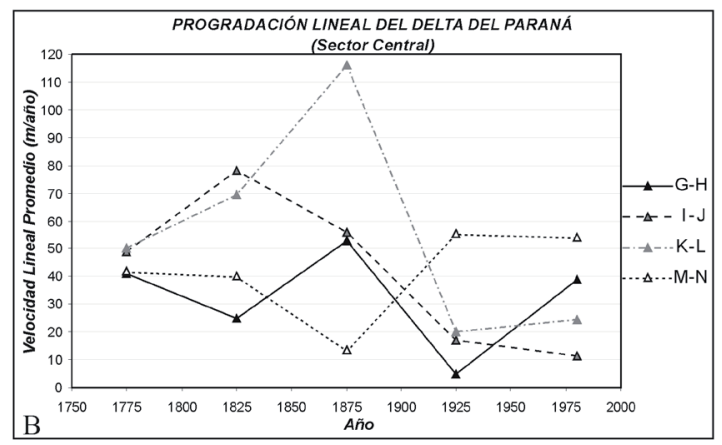

Velocidad Lineal Promedio (1750-2010)

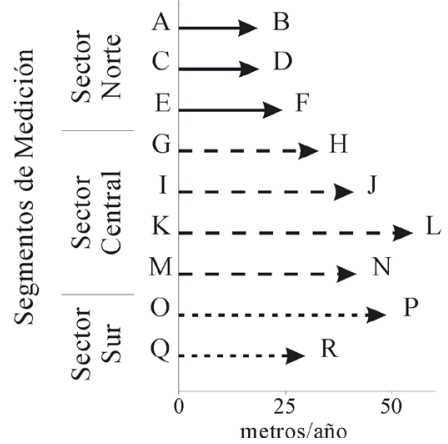

Fig. 4. Velocidades promedio de progradación lineal del delta del río Paraná medido a lo largo de nueve ejes distribuidos a lo ancho del sector analizado. Para la ubicación de los respectivos ejes remitirse al mapa de la figura 3.

anteriores, a unos $30 \mathrm{~m} / \mathrm{año} \mathrm{(segmento} \mathrm{Q-R).}$

Sin embargo, el análisis de las velocidades lineales promedio tomadas cada intervalos de 50 años muestra un esquema evolutivo distinto. Acá se destacan diferentes picos de crecimiento en los distintos sectores y en diferentes períodos de tiempo. A éstos le suceden, por lo general, períodos con una tasa de crecimiento baja a muy baja. Procesos similares de acelerado crecimiento también se observan a otras escalas de análisis, particularmente vinculado a la evolución de las islas del delta, señalándose como ejemplo al Complejo isleño Martín García-Timoteo Domínguez, al is- lote El Matón y a la isla Juncal (Fig. 5).

Teniendo en cuenta que la mayoría de los datos de la figura 2 se concentró en los años más recientes, se procedió a analizar en detalle el período 1900-2010, llegándose a conclusiones relativamente similares (Fig. 6). En este período, el delta del Paraná creció aproximadamente $270 \mathrm{~km}^{2}$ a una tasa constante de 236 ha/año $\left(\mathrm{R}^{2}=0,99\right)$, valor levemente inferior al registrado para el período completo antes analizado (1775-2010).

Con un criterio similar al análisis precedente, pero priorizando la calidad en vez de la cantidad de datos, se analizó el período 1976-2010 donde 


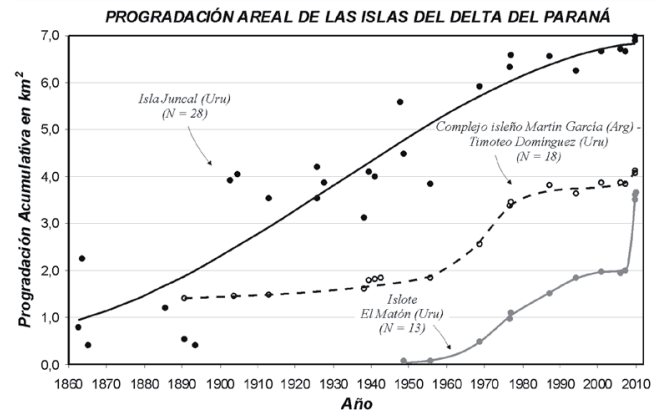

Fig. 5. Progradación areal del Complejo isleño Martín García (Arg)-Timoteo Domínguez (Uru), del islote El Matón (Uru) y de la isla Juncal (Uru). Se aprecia el acelerado crecimiento areal debido probablemente al eficaz entrampamiento de sedimentos finos por parte de la vegetación allí presente. Luego de este período la tasa de crecimiento areal decae por lo general a valores insignificantes.

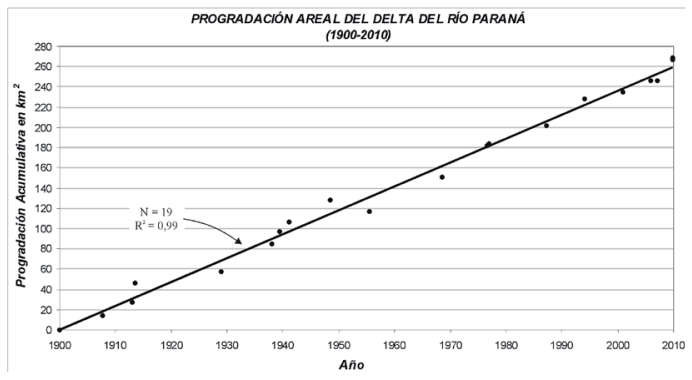

Fig. 6. Crecimientoareal del deltadel río Paranáparael período 1900-2010. Se observa un incremento de aproximadamente $270 \mathrm{~km}^{2}$ a una tasa constante de $236 \mathrm{ha} /$ año.

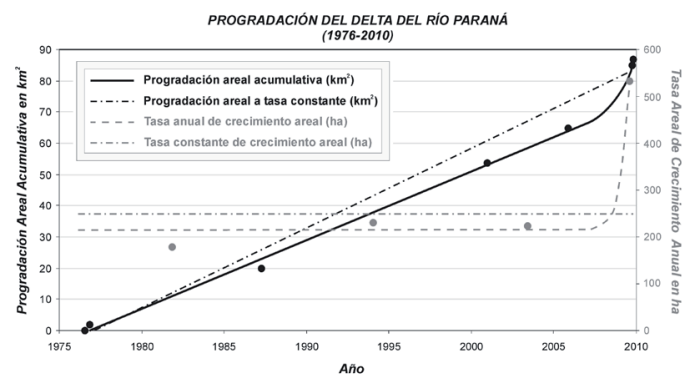

Fig. 7. Crecimiento areal del delta del río Paraná (período 1976-2010). Se aprecia un incremento de alrededor de $87 \mathrm{~km}^{2}$ a una tasa promedio de $249 \mathrm{ha}$ año. Una evolución más ajustada a los datos disponibles sugiere un crecimiento a tasa constante de 219 ha/ año hasta el año 2005, con un posterior crecimiento exponencial que alcanza en el 2010 una tasa superior al doble de la registrada en el siglo XX.

la completa cobertura satelital permitió efectuar mediciones con mayor precisión y exactitud. En este lapso el delta creció alrededor de $87 \mathrm{~km}^{2}$ a una tasa promedio de 249 ha/año. No obstante, el detallado análisis permitió distinguir dos ritmos de avance distintos. El primero abarcó hasta el año 2005 aproximadamente, y estuvo caracteri- zado por un crecimiento areal constante de 219 ha/año, en tanto el segundo se destacó por un fuerte crecimiento exponencial alcanzando en el año 2010 una tasa anual superior a las 550 ha (Fig. 7).

\section{DISCUSIÓN}

Entre los efectos debido al calentamiento global se prevén incrementos en la tasa de erosión de las costas marinas de todo el mundo, y en particular, de las costas deltaicas (Okude \& Ademiluyi, 2006; Syvitski et al., 2009). En el Río de la Plata, estos efectos se evidencian directa o indirectamente en el leve pero continuo ascenso del nivel medio del mar, en el incremento de la frecuencia de eventos de tormentas marítimas (sudestadas), en el cambio en la dirección, frecuencia y velocidad de los vientos con su correlato en la frecuencia, altura y dirección de olas, y probablemente en el retroceso desde mediados del siglo pasado de la línea de costa de la bahía Samborombón (Codignotto et al., 2011a; Codignotto et al., 2012 y Dragani et al., 2012). Estos mismos procesos desencadenados por el calentamiento global seguramente han actuado en las costas bajas del delta del Paraná. Sin embargo, en este último sector los procesos erosivos no se manifiestan claramente pues, según los estudios realizados, no se ha evidenciado, por ejemplo, una neta disminución del ritmo de avance del cuerpo deltaico. Los estudios efectuados contemplaron tres escalas de análisis temporales diferentes: $1775-2010,1900-2010$ y 1976-2010. En las dos primeras el crecimiento fue de tipo lineal a una tasa de 264 y 236 ha/año, respectivamente. En principio se torna arriesgado considerar esta disminución como una consecuencia directa del calentamiento global, pues quizás sólo sea el reflejo de la escasez de datos del primer período respecto al segundo con relación a los períodos de tiempo considerados ( 24 y 19 datos en 235 y 110 años, respectivamente). Por otra parte, el tercer período registra una tasa promedio de 249 ha/ año, con un crecimiento a tasa constante de 219 ha/año hasta aproximadamente el 2005, con un posterior crecimiento exponencial que alcanza en el 2010 una tasa superior a las 550 ha/año. Si bien esta variabilidad podría adjudicarse a las consecuencias del calentamiento global, es realmente difícil discernir entre éstas y las propias debidas a procesos periódicos y de corto alcance que responden a la variabilidad climática local como por ejemplo el fenómeno ENOS (El Niño/ Oscilación del Sur y su contrapartida La Niña). 
Por tanto, y a diferencia de los restantes deltas del mundo, la dinámica evolutiva actual del delta del río Paraná no parece verse afectada por los cambios en las magnitudes de las variables intervinientes en el sistema climático. Es más, si en un futuro próximo se confirma el crecimiento exponencial registrado desde el año 2005 al presente, se estará frente a una consecuencia de signo opuesto al generalmente esperado para este tipo de ambiente. En otras palabras, se estará frente a un incremento en la tasa de progradación areal en vez de asistir a su paulatina disminución.

Sin embargo no hay que olvidar que todo delta es consecuencia de un balance positivo entre la carga sedimentaria aportada por un curso fluvial y la redistribución de esa carga ejercida por el cuerpo de agua receptor. Es evidente que al incrementarse este último proceso en el Río de la Plata debió haberse incrementado en igual o mayor medida el aporte sedimentario por parte del río Paraná, dado el constante avance registrado por el delta homónimo. En el presente, lamentablemente no existen estudios comparativos que relacionen el aporte sedimentario actual y del pasado reciente. Sin embargo, el ciclo húmedo registrado desde la década del 70 en la región centro y norte de la Argentina (Hoffmann et al., 1987) probablemente ha incrementado el aporte sedimentario a los cursos fluviales al aumentar la escorrentía superficial y la erosión hídrica asociada. Por otra parte, este ciclo húmedo ha favorecido el cambio en el uso del suelo en la región al posibilitar la extensión de la frontera agrícola hacia el oeste, causando una mayor deforestación y diversos cambios en el manejo agroganadero (Reboratti, 2010a, b). Estos cambios posiblemente favorecieron el mayor transporte de sedimentos hacia los cursos fluviales. Es sabido que la cobertura forestal protege al suelo de la erosión hídrica, particularmente en zonas de pendiente, y el cultivo tradicional empleado en los años 70, al ser ávido en técnicas de arado, dejaba al suelo momentáneamente sin cobertura vegetal ni rastrojos, desprotegiéndolo frente a la acción erosiva hídrica y eólica. Estos procesos en parte recién fueron remediados hacia la década del ' 90 al emplear técnicas más conservacionistas como por ejemplo labores del tipo de Siembra Directa. Sin embargo, este mal uso del recurso suelo no fue privativo del norte argentino. En la provincia de Buenos Aires, por causas similares en donde ha prevalecido claramente la visión económica a corto plazo, se han detectado índices de erosión superiores al tolerable para un uso sustentable del recurso que afecta directamente la capacidad productiva de la tierra (Pienovi \& Latour, 2011).
Por último, cabe señalar que un estudio no integral del delta del río Paraná puede inducir a conclusiones erróneas acerca de su dinámica actual. Esto es particularmente cierto para el caso de las velocidades de progradación lineal, en donde las aceleraciones y desaceleraciones responden sólo a la dinámica de un determinado sector en un determinado período de tiempo, y no reflejan por ende el comportamiento del delta en su conjunto. En este sentido, y tal cual como queda reflejado en la figura 4, un determinado incremento en la velocidad de progradación lineal en un sector y período de tiempo dado, puede coexistir con un decrecimiento en la velocidad de avance en otro sector en el mismo intervalo de tiempo. Esto es así pues probablemente las aceleraciones respondan a la emersión y subsecuente y rápida colonización vegetal de los bancos arenosos que lentamente se han depositado en el lugar. Es decir, no obedece a una mayor carga sedimentaria aportada por el río en ese sector, sino a un eficaz proceso de entrampamiento de esos sedimentos, particularmente los de granulometría fina, que de otro modo habrían pasado a formar parte del sector de prodelta. Las desaceleraciones, por su parte, reflejarían la lenta pero continua conformación de los bancos arenosos anteriormente citados.

\section{CONCLUSIONES}

En dos áreas próximas con similares características (costas bajas e influencia antrópica despreciable), los múltiples efectos del calentamiento global han provocado fenómenos contrastantes de erosión y progradación. En la bahía Samborombón han predominado los procesos erosivos evidenciados por un notable retroceso de su costa. En el delta del Paraná, si bien esos mismos procesos están presentes, prevalece allí un constante avance de su frente costero, de hecho incluso se ha insinuado una leve aceleración. Es probable que este último comportamiento sea causado por un mayor aporte de sedimentos al Paraná debido al cambio en el régimen de precipitaciones en el centro y norte de Argentina. $\mathrm{Al}$ ser esto una consecuencia directa del calentamiento global, o en su defecto, de la variabilidad climática regional, se puede afirmar que el factor climático es también responsable de la dinámica progradacional anteriormente citada.

\section{AGRADECIMIENTOS}

Al Dr. R. Kokot y al Dr. A. Monti por las correcciones y sugerencias. A la Lic. A. L. Martínez 
por la lectura crítica del trabajo e invalorables comentarios. Al personal de la mapoteca "Manuel Selva" de la Biblioteca Nacional, de la biblioteca "Romualdo Ardissone" de la Facultad de Filosofía y Letras (UBA) y del Departamento de Documentos Escritos del Archivo General de la Nación, por la gentileza y denodado esfuerzo en buscar y conseguir el imprescindible material cartográfico necesario para esta investigación. $\mathrm{Y}$ al Global Land Cover Facility (www.landcover.org), a la Comisión Nacional de Actividades Espaciales (CONAE) y al Instituto Geográfico Nacional (IGN), por facilitar la adquisición de las imágenes satelitales.

\section{BIBLIOGRAFÍA}

Allison M.A. 1998. Historical changes on the GangesBrahmaputra delta front. Journal of Coastal Research, 14(4): 1269-1275.

Bird E.C. 2008. Coastal geomorphology. An introduction. John Wiley \& Sons Ltd, 411 pp., Chichester.

Camilloni I.A. 1999. Temporal variability of the Buenos Aires' urban heat island intensity. International Conference on Urban Climatology ICUC '99, Sydney.

Camilloni I.A. 2005. Tendencias climáticas. En: Barros V., A. Menéndez \& G. Nagy (eds.) El cambio climático en el río de la Plata, 13-19, Bs As.

Camilloni I.A., V.R. Barros \& A. Di Luca. 2005. Trends in the position of the South Atlantic high and its representation by Global Climate Models: impacts over the río de la Plata estuary and adjacent ocean (in Spanish). Preprints of IX Congreso Argentino de Meteorología (CD-ROM), Bs As.

Cavallotto J.L., R.A. Violante \& F. Colombo. 2005. Evolución y cambios ambientales de la llanura costera de la cabecera del río de la Plata. Revista de la Asociación Geológica Argentina, 60(2): 353-367, Bs As.

Codignotto J.O. 1990. Avance del delta del Paraná y la isla Martín García. Actas XI Congreso Geológico Argentino, T. I: 272-275, San Juan.

Codignotto J.O. 1996. El delta del Paraná y el estuario del río de la Plata. Excursión Geológica Intracongreso "Isla Martín García”, XIII Congreso Geológico Argentino y III Congreso de Exploración de Hidrocarburos, 10 pp., Bs As.

Codignotto J.O. 2009. Cambios de contorno de la costa atlántica Argentina. Anales Academia Nacional de Geografía, 30: 101-134, Bs As.

Codignotto J.O. \& B. Ercolano. 2006. Incremento de la erosión costera en Argentina. VI Jornadas Nacionales de Ciencias del Mar, p. 147, Centro Nacional Patagónico (CONICET-UNPSJB-UTN), Chubut.

Codignotto J.O. \& R.A. Medina. 2005. Morfodinámica del delta del río Paraná y su vinculación con el cambio climático. Actas XVI Congreso Geológico Argentino, T. III: 651-656, La Plata, Bs As.
Codignotto J.O. \& R.A. Medina. 2011. Evolución geomorfológica del delta del Paraná. En: Quintana R., M. Villar, E. Astrada, P. Saccone \& S. Malzof (eds.) El Patrimonio natural y cultural del Bajo Delta Insular. Bases para su conservación y uso sostenible. Ed. Aprendelta, Cap. 5: 66-75, Bs As.

Codignotto J.O., C.L. Herrera \& C.A. Aiello. 1996. Río de la Plata: fenómenos antrópicos, geodinámicos y legislación sobre uso costero. Revista de la Asociación Argentina de Geología Aplicada a la Ingeniería, X: 82-93, Bs As.

Codignotto J.O., W.C. Dragani, P.B. Martin, C.G. Simionato \& R.A. Medina. 2011a. Incremento de erosión en la bahía Samborombón, río de la Plata, Argentina. Actas XVIII Congreso Geológico Argentino, 262-263, Neuquén.

Codignotto J.O., W.C. Dragani, P.B. Martin, M.I. Campos, G. Alonso, C.G. Simionato \& R.A. Medina. 2011b. Erosión en la bahía Samborombón y cambios en la dirección de los vientos, provincia de Buenos Aires, Argentina. Revista Museo Argentino Ciencias Naturales, n.s, 13(2): 135-138, Bs As.

Codignotto J.O., W.C. Dragani, P.B. Martin, C.G. Simionato, R.A. Medina \& G. Alonso. 2012. Windwave climate change and increasing erosion observed in the outer río de la Plata, Argentina. Continental Shelf Research, 38: 110-116.

De Lapparent A.A. 1906. Traité de Géologie. Masson et Cie, T. I, 591 pp., París.

Dragani W.C., J.O. Codignotto, P.B. Martin, M.I. Campos, G. Alonso, C.G. Simionato \& R.A. Medina. 2012. Some coastal impacts related to wind wave changes in the South-Eastern South American Continental Shelf. Nova Science Publishers, Serie Horizons in Earth Science Research, V. 6, Cap. 5: 161-177, New York.

Escobar G.C., I.A. Camilloni \& V.R. Barros. 2003. Desplazamiento del anticiclón subtropical del Atlántico Sur y su relación con el cambio de vientos sobre el estuario del río de la Plata. Anales $X$ Congreso Latinoamericano Ibérico de Meteorología (CD-ROM), La Habana.

Escobar G.C., W.M. Vargas \& S.A. Bischoff. 2004. Wind tides in the río de la Plata estuary: meteorological conditions. International Journal of Climatology, 24: 1159-1169.

Gibson T.T. 1992. An observed poleward shift of the Southern Hemisphere Subtropical wind maximum: A greenhouse symptom?. International Journal of Climatology, 12: 637-640.

Groeber P.F. 1961. Contribución al conocimiento geológico del delta del Paraná y alrededores. Anales Comisión de Investigaciones Científicas, 2: 9-54, La Plata, Bs As.

Hoffmann J.A., S.E. Nuñez \& A.T. Gómez. 1987. Fluctuaciones de la precipitación en la Argentina, en lo que va del siglo. Anales II Congreso Interamericano de Meteorología y V Congreso Argentino de Meteorología, 12.1.1-12.1.5, Bs As.

IPCC. 1990. Climate change - The IPCC scientific assessment. IPCC First Assessment Report, Cambridge University Press, 365 pp., Cambridge 
and Sydney.

IPCC. 1995. Climate change - Impacts, adaptation and mitigation of climate change: scientifictechnical analysis. Contribution of Working Group II to the Second Assessment Report of the Intergovernmental Panel on Climate Change, Cambridge University Press, 878 pp., Cambridge and New York.

IPCC. 2001. Climate change - Impacts, adaptation and vulnerability. Contribution of Working Group II to the Third Assessment Report of the Intergovernmental Panel on Climate Change, Cambridge University Press, 1032 pp., Cambridge and New York.

IPCC. 2007. Climate change 2007: The physical science basis. Summary for Policymakers. IPCC, WGI Fourth Assessment Report, Cambridge University Press, 18 pp., Cambridge and New York.

Iriondo M.H. 1980. Esquema evolutivo del delta del Paraná durante el Holoceno. Actas Simposio sobre problemas geológicos del Litoral Atlántico Bonaerense, 74-88, Mar del Plata, Bs As.

Iriondo M.H. 2004. The littoral complex at the Paraná mouth. Quaternary International, 114: 143-154.

Iriondo M.H. \& E. Scotta. 1979. The evolution of the Paraná river delta. Proceedings of the 1978 International Symposium on Coastal Evolution in the Quaternary, 405-418, São Pablo.

Kokot R.R. 1997. Littoral Drift, Evolution and Management in Punta Médanos, Argentina. Journal of Coastal Research, 13(1): 192-197.

Kokot R.R. 1999. Cambio climático y evolución costera en Argentina. Tesis doctoral, Dpto. de Geología, Facultad de Ciencias Exactas y Naturales, UBA, 329 pp., Bs As. Inédito.

Kokot R.R. 2010. Espigas indicadoras de proveniencia de olas en la costa argentina. Revista de la Asociación Geológica Argentina, 67(1): 19-26, Bs As.

Lanfredi N.W., J.L. Pousa \& E.E. D’Onofrio. 1998. Sea level rise and related potential hazards on the Argentine coast. Journal of Coastal Research, 14(1): 47-60.

Malvárez A.I. 1997. Las comunidades vegetales del Delta del río Paraná. Su relación con factores ambientales y patrones de paisaje. Tesis doctoral, Facultad de Ciencias Exactas y Naturales, UBA, 167 pp., Bs As. Inédito.

Medina R.A. 2004. Recopilación bibliográfica y cartográfica correspondiente al delta del Paraná y la bahía Samborombón. Informe Final Beca UBA, 92 pp., Bs As. Inédito.

Medina R.A. \& J.O. Codignotto. 2011. Morfodinámica histórica del delta del Paraná (1750-2010). Actas XVIII Congreso Geológico Argentino, 297-298, Neuquén.

Medina R.A. \& J.O. Codignotto. 2012. Efectos del cambio climático en la evolución geomorfológica del bajo delta del río Paraná. Actas $V$ Congreso Argentino de Cuaternario y Geomorfología, 94-95, Río Cuarto, Córdoba.

Medina R.A., J.O. Codignotto, W.C. Dragani, A.L.
Martínez, P.B. Martin, C.G. Simionato \& G. Alonso. 2011. Impacto del cambio climático en el delta del Paraná y en la bahía Samborombón. Actas III Jornadas Interdisciplinarias de Cambio Climático de la Universidad de Buenos Aires (PIUBACC), p. 66 , Bs As.

Muñiz F.J. 1925. Noticia sobre las yslas del parana. Publicaciones del Instituto de Investigaciones Geográficas, Facultad de Filosofía y Letras, UBA, № 9: 15-24, Bs As.

Nossin J.J. 1965. The geomorphic history of the Padang delta. Journal of Tropical Geography, 20: 54-64.

O’Day K. 2012. http:/chartsgraphs.wordpres.com/

Okude A.S. \& I.A. Ademiluyi. 2006. Coastal erosion phenomenon in Nigeria: Causes, control and implications. World Applied Sciences Journal, 1: 44 -51.

Pienovi A. \& A. Latour. 2011. Erosión de la tierra en el noreste bonaerense, influencia del cambio climático. Soluciones. Actas III Jornadas Interdisciplinarias de Cambio Climático de la Universidad de Buenos Aires (PIUBACC), p. 81, Bs As.

Reboratti C.E. 2010a. Impactos de la expansión agropecuaria sobre la sociedad y el ambiente. En: C. Reboratti (ed) Agricultura, Sociedad y Ambiente. Miradas y conflictos. Serie Monografías 2, Cap. 9: 163-183, Bs As.

Reboratti C.E. 2010b. Un mar de soja: la nueva agricultura en Argentina y sus consecuencias. Revista de Geografía Norte Grande, 45: 63-76.

Sarubbi A., M.G. Pittau \& A.N. Menéndez. 2006. Delta del Paraná: avance del frente e incremento areal. Informe Laboratorio de Hidráulica 05-235-06, Instituto Nacional del Agua, 54 pp., Ezeiza, Bs As.

Sarubbi A. 2007. Análisis del avance del frente del delta del río Paraná. Tesis de grado en Ingeniería Civil, Facultad de Ingeniería, UBA, 136 pp., Bs As. Inédito.

Simionato C.G., C.S. Vera \& F. Siegismund. 2005. Surface wind variability on seasonal and interannual scales over río de la Plata. Journal of Coastal Research, 21(4): 770-783.

SMN. 1992. Estadísticas climatológicas 1981-1990. Serie B - N³7. Fuerza Aérea Argentina, Comando de Regiones Aéreas, Servicio Meteorológico Nacional, $710 \mathrm{pp}$.

SMN. 2009. Estadísticas climatológicas 1991-2000. Fuerza Aérea Argentina, Servicio Meteorológico Nacional. CD-ROM.

Soldano F.A. 1947. Régimen y aprovechamiento de la red fluvial Argentina. Parte I: El río Paraná y sus tributarios. Editorial Cimera, 264 pp., Bs As.

Syvitski J.P., A.J. Kettner, I. Overeem, E.W. Hutton, M.T. Hannon, G.R. Brakenridge, J. Day, C. Vörösmarty, Y. Saito, L. Giosan \& R.J. Nicholls. 2009. Sinking deltas due to human activities. Nature Geoscience, Publicación online, DOI: 10.1038/NGEO629.

Vignati M.A. 1925. Introducción. Publicaciones del Instituto de Investigaciones Geográficas, Facultad de Filosofía y Letras, UBA, № 9: 3-14, Bs As.

Recibido: 29-VIII-2012 Aceptado: 6-XI-2013 